Check for updates

Cite this: RSC Adv., 2018, 8, 36090

\title{
A simple preparation method of carbon dots by weak power bathroom lamp irradiation and their application for nimesulide detection and bioimaging $\dagger$
}

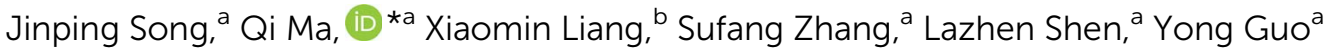 \\ and Feng Feng ${ }^{a}$
}

In this work, a novel strategy for synthesizing carbon dots (CDs) with a quantum yield of approximately $15.36 \%$ has been established by employing a bathroom lamp as a light source. Compared with other current protocols, the method described here displayed various advantages such as environmentally friendly manipulations and low power and cost. Subsequently, we applied the CDs as a fluorescence probe for the detection of nimesulide (Nim) firstly under the optimal conditions. A linear relationship between $\ln \left(F_{0} / F\right)$ and the concentration of Nim was obtained in the range from $0.5 \mu \mathrm{M}$ to $75 \mu \mathrm{M}$ with a detection limit of $100 \mathrm{nM}$. In addition, the as-prepared CDs showed excellent biocompatibility and were applied for cell imaging, which presented great potential applications in cell imaging.

Received 26th July 2018

Accepted 10th October 2018

DOI: $10.1039 / \mathrm{c} 8 \mathrm{ra06313c}$

rsc.li/rsc-advances

nanostructures). However, laser ablation belongs to a stronger power irradiation and requires expensive and sophisticated instrumentation, and does not apply to large scale preparation of CDs, which severely limits the practical applications of CDs. Therefore, it is very necessary to develop a new method with low power and cost for the preparation of CDs. Inspired by laser ablation, based on the interest for CDs preparation by lightirradiation methods, we looked for a low-power and economic bathroom lamp as a light source. In addition, we also further explored its potential applications.

Nimesulide

( $N$-(4-nitro-2-phenoxyphenyl)-methanesulphonamide, Nim) is a relatively new non-steroidal antiinflammatory drug with analgesic and antipyretic properties. Nim's $\mathrm{p} K_{\mathrm{a}}$ value of 6.5 is very important for gastric tolerability, as it avoids the back diffusion of hydrogen ions responsible for tissue damage, which does not induce gastrointestinal ulceration. ${ }^{17} \mathrm{Nim}$ is also a strong inhibitor of metalloproteases, enzymes that along with free radicals account for matrix decomposition of the articular molecule in the degenerative process. It also exerts an indirect inhibiting effect on A2 phospholipase. Therefore, Nim is widely used as a therapeutic medicine. However, long term or excessive use of Nim will cause severe side effects including in the hepatic and central nervous systems for children and adults. ${ }^{18}$ Thus, it is quite important to detect Nim in drugs and biological samples separation.

Until now, various detection methods have been employed for the detection of Nim, including high-performance liquid chromatography (HPLC), ${ }^{19-22}$ semiconductor quantum dots, ${ }^{23}$ batch injection analysis, ${ }^{24}$ and electroanalytical methods. ${ }^{25-32}$

$\dagger$ Electronic supplementary information (ESI) available. See DOI: 10.1039/c8ra06313c 
These methods may provide high sensitivity and good precision, but these methods are time-consuming and commonly suffered from operation complexity, materials consumption and expensive equipment. In comparison with reported analytical techniques, besides high sensitivity and selectivity, fluorescence methods are more convenient, fast and economical in trace analysis. So far, to our knowledge, there is no literature reporting on the fluorescence detection of Nim based on CDs.

In this study, a simple preparation method of CDs was developed by low power and low-cost bathroom lamp irradiation, and we firstly reported a highly selective and sensitive fluorescence sensor for the detection of Nim based on CDs. We demonstrate the use of citric acid as a carbon source for softlight irradiation green synthesis of water-soluble, PL CDs with a quantum yield (QY) of approximately $15.36 \%$. We further demonstrate that the as-synthesized CDs are an effective fluorescent probe for the sensitive and selective detection of Nim with a detection limit as low as $100 \mathrm{nM}$. The linear range is estimated to be the feasibility of the CDs for successful analysis of Nim in a real sample.

\section{Experimental section}

\subsection{Materials and reagents}

Citric acid and all metal salts $\left(\mathrm{CdCl}_{2}, \mathrm{MgCl}_{2}, \mathrm{ZnCl}_{2}, \mathrm{CrCl}_{3}, \mathrm{AlCl}_{3}\right.$, $\mathrm{CaCl}_{2}, \mathrm{BaCl}_{2}, \mathrm{NiCl}_{2}, \mathrm{PbCl}_{2}, \mathrm{MnCl}_{2}, \mathrm{HgCl}_{2}, \mathrm{CuCl}_{2}, \mathrm{FeCl}_{2}, \mathrm{FeCl}_{3}$ and $\mathrm{AgNO}_{3}$ ) were purchased from Beijing Chemical Reagents Factory (Beijing, China). Nim, ibuprofen and 4-acetamidophenol were purchased from Aladdin Chemistry Reagent Company (Shanghai, China). All chemicals were analytical reagent grade and used directly. Ultrapure water was obtained by Millipore Milli-Q plus 185 water purification system and used in all experiments.

\subsection{Synthesis of CDs}

The CDs were synthesized by using a bathroom lamp irradiated citric acid solution. In a typical experiment, $2.0 \mathrm{~g}$ of citric acid was dissolved in $5.0 \mathrm{~mL}$ of ultrapure water at room temperature. The mixture was ultrasonically dispersed for $5 \mathrm{~min}$. Next, the mixture solution was transferred into a $25 \mathrm{~mL}$ beaker and placed under a bathroom lamp $(275 \mathrm{~W})$. The irradiation time was carried out for $2 \mathrm{~h}$. The obtained products were cooled down to room temperature and further ground into powder. The obtained powder was redispersed into ultrapure water and filtered through the filtration membrane $(0.22 \mu \mathrm{m})$ to remove large particle residues. Subsequently, the filtrated solution was dried by a freeze-drying process.

\subsection{Determination of quantum yield (QY)}

The QY $(\Phi)$ of the CDs was measured according to a reported method. ${ }^{33}$ Quinine sulfate in $0.1 \mathrm{M} \mathrm{H}_{2} \mathrm{SO}_{4}$ was employed as a reference standard $\left(\Phi_{\text {std }}=0.54\right.$ at $\left.350 \mathrm{~nm}\right)$. The relative fluorescence QY of CDs was calculated via the following equation:

$$
\Phi_{\mathrm{x}}=\Phi_{\text {std }} \frac{I_{\mathrm{x}}}{A_{\mathrm{x}}} \frac{A_{\text {std }}}{I_{\text {std }}} \frac{\eta_{\mathrm{x}}{ }^{2}}{\eta_{\mathrm{std}}{ }^{2}}
$$

where $\Phi_{\mathrm{x}}$ is the fluorescence QY, $I$ is the measured integrated fluorescence intensity, $A$ is the optical density. $\eta$ is the refractive index of the solvent. The subscript $\mathrm{x}$ and std refer to the CDs and the reference, respectively. To avoid the re-absorption effect, the absorbance of all the samples in the $10 \mathrm{~mm}$ path length fluorescence cuvette should be adjusted to less than 0.10 at the excitation wavelength.

\subsection{Characterization}

The morphology of the CDs was determined by a JEOL JEM-2100 transmission electron microscope (Tokyo, Japan). X-ray photoelectron spectra were obtained by a PHI-5400 electron spectrometer (ULVCA-PHI, USA). X-ray powder diffraction (XRD) was obtained using a Bruker D8 Advance. UV-vis absorption spectra were recorded on a Perkin-Elmer Lambda 35 UV-vis spectrometer (PE, USA). Fluorescence spectra were measured with a Cary Eclipse Fluorescence Spectrophotometer (Varian, USA). Cell imaging experiments were carried out on an Olympus FV1000 confocal microscope (Tokyo, Japan). Dynamic light scattering (DLS) was performed with a Zeta plus particle size analyzer instrument (Brookhaven, USA).

\subsection{Cell imaging experiments}

HeLa cells and adipose-derived stem cells (ADSC) were cultured at $37{ }^{\circ} \mathrm{C}$ in DMEM medium containing $10 \%$ fetal bovine serum (FBS) in a $5 \% \mathrm{CO}_{2}$ atmosphere. Then, HeLa cells and ADSC were further incubated in CDs aqueous solution $\left(200 \mu \mathrm{g} \mathrm{mL}^{-1}\right)$ for 0.5 and $1 \mathrm{~h}$, respectively. Afterwards, HeLa (or ADSC) cells were further treated with $0.25 \%$ trypsin $/ 0.020 \%$ EDTA, washed three times using the PBS buffer ( $\mathrm{pH}$ 7.4) and kept in PBS for fluorescence imaging. The images of the cells were immediately determined on an Olympus FV1000 confocal microscope. The excitation wavelength was set as $405 \mathrm{~nm}$ and the corresponding blue emissions were collected at $425-525 \mathrm{~nm}$.

\section{Results and discussion}

\subsection{Synthesis and characterization of CDs}

The synthesis of CDs in this work is a rather simple, low-cost and environmentally-friendly one-step bathroom lamp irradiation method (Fig. 1). CDs with blue PL could be obtained by employing citric acid as an organic carbon source. In order to obtain the desired products, a series of experimental conditions have been optimized. It was found that the irradiation time and the distance between the bathroom lamp and the sample could affect the quantum yields of the CDs. With the increase of the irradiation time, the QY of the CDs gradually increased and reached a maximum, afterwards, the QY gradually dropped (Fig. S1 in ESI $\dagger$ ). The reasonable explanation is that a short irradiation time was not enough for complete carbonization of the carbon source because of insufficient reaction energy, while a long reaction time would lead to the formation of larger and nonuniform carbogenic particles due to aggregation. In this 


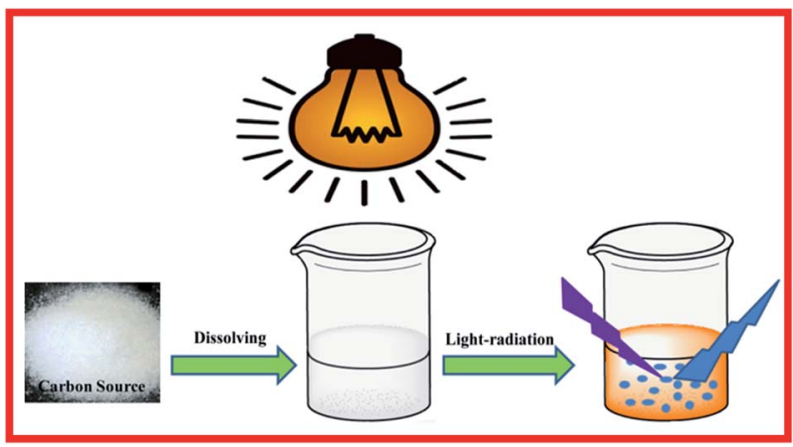

Fig. 1 Schematic diagram of CDs preparation by a photo-irradiation method.

case, the optimal irradiation time was $120 \mathrm{~min}$. Under the optimal photo-irradiation time, the effect of the distance between the lamp and the sample on the QY of CDs was shown in Fig. S2. $\dagger$ Obviously, the QY of the CDs firstly increased and reached a maximum, then dropped gradually with increasing distance between the lamp and the sample. The optimum photo-irradiation distances were $16 \mathrm{~cm}$ for the preparation of CDs. The maximum QY of the CDs was $15.36 \%$.

Fig. 2 showed the TEM image and size distribution of the prepared CDs. CDs are quasi-spherical particles and have a uniform dispersion without apparent aggregation. Size distribution results demonstrated that the diameters of CDs are mainly distributed within $5.5-7.5 \mathrm{~nm}$, and the corresponding average diameter was approximately $6.6(27.78 \%)$, indicating that the as-synthesized CDs are highly monodispersed in aqueous solution.

XPS techniques were used to study the functional groups and element states of the as-synthesized CDs. As shown in Fig. 3, the
XPS spectrum of the CDs showed two peaks at $\sim 285 \mathrm{eV}$ and $\sim 532 \mathrm{eV}$, which were attributed to the $\mathrm{C}_{1 \mathrm{~s}}$ and $\mathrm{O}_{1 \mathrm{~s}}$ peak. The $\mathrm{C}: \mathrm{O}$ atom ratio was $1.53: 1.00$. In the high-resolution $\mathrm{C}_{1 \mathrm{~s}}$ spectrum, the CDs mainly included four surface components, corresponding to $\mathrm{C}-\mathrm{H}(\sim 283.1 \mathrm{eV}), \mathrm{C}-\mathrm{C} / \mathrm{C}=\mathrm{C}(\sim 284.7 \mathrm{eV}$, $\sim 285.8 \mathrm{eV}), \mathrm{C}-\mathrm{O}(\sim 286.3 \mathrm{eV})$ and $\mathrm{C}=\mathrm{O}(\sim 287.3 \mathrm{eV})$. In the highresolution $\mathrm{O}_{1 \mathrm{~s}}$ spectrum, the two main peaks located at $\sim 531.2 \mathrm{eV}$ and $532.5 \mathrm{eV}$ were ascribed to the $\mathrm{C}=\mathrm{O}$ and $\mathrm{C}-\mathrm{O}$ groups. $^{34,35}$ Furthermore, the XRD pattern displayed a broad, low-intensity diffraction peak centered at $20.25^{\circ}$, which is indicative of the highly disordered carbon atoms. ${ }^{36}$

\subsection{Photoluminescence properties and stability of CDs}

Fig. 4 depicted the UV-vis absorption and PL spectra of CDs. It was observed that there was an obvious broad absorption peak at $326 \mathrm{~nm}$, which was attributed to $\mathrm{n}-\pi^{*}$ transition of $\mathrm{C}=\mathrm{O}$. The resultant CDs exhibited a maximum emission peak at $457 \mathrm{~nm}$ under $340 \mathrm{~nm}$ excitation wavelength. With progressively increasing excitation wavelengths, it was found that the PL intensity of CDs increases firstly and reaches a maximum value but the fluorescence emission peak remains constant.

Hereafter, with further increase of the excitation wavelength, it was noticed that the fluorescence emission wavelength redshifted to longer wavelengths, which was accompanied with a decrease of PL intensity. The excitation-dependent PL behavior may be ascribed to the different particle sizes and the distribution of different surface states as in the case of most fluorescent carbon dots. The absolute QY of CDs was calculated to be $15.36 \%$. In addition, as displayed in the inset of Fig. 4, CDs presented as yellow under visible light, whereas they exhibited a bright blue luminescence under excitation at $365 \mathrm{~nm}$. These results verified that the photo-irradiation method was
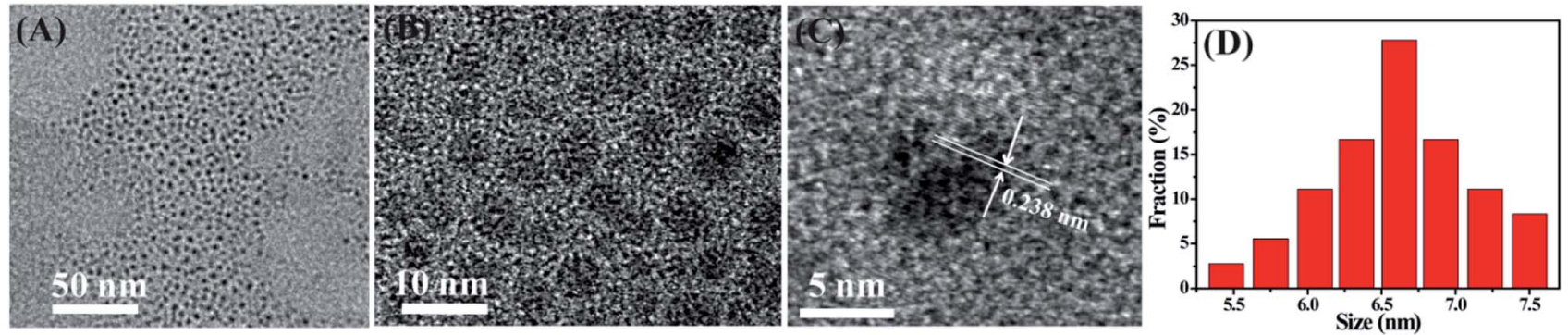

Fig. 2 TEM (A) and HRTEM (B and C) images and size distribution (D) of the CDs.
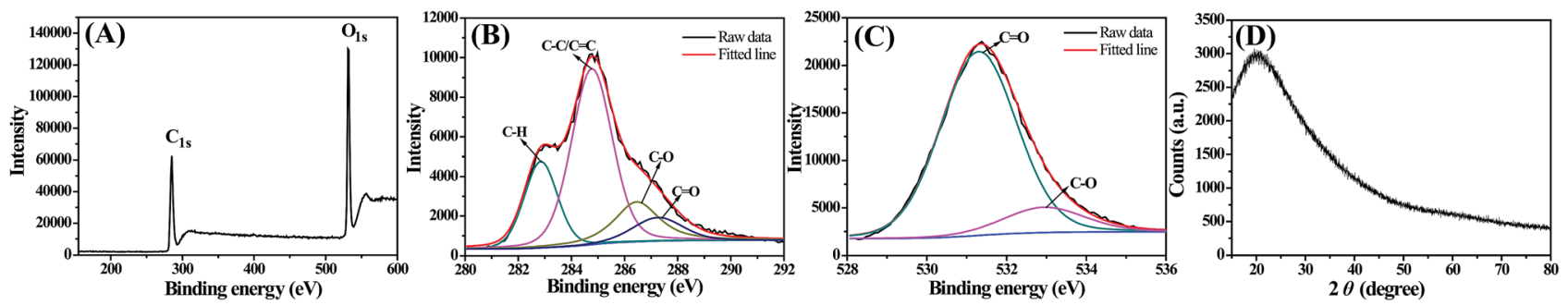

Fig. 3 (A) XPS survey spectra of the CDs, and the corresponding $C_{1 s}(B), O_{1 s}(C)$ and (D) XRD patterns of CDs. 


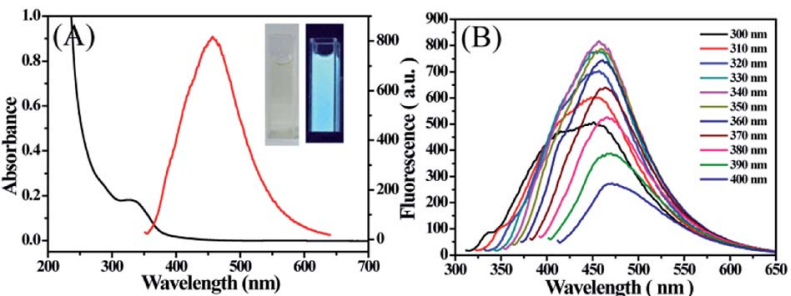

Fig. 4 (A) UV-vis absorption (black line) and fluorescence (red line) spectra of the CD solution. The inset is the image of the CDs under sunlight and under $365 \mathrm{~nm}$ UV irradiation. (B) Fluorescence spectra of $\mathrm{CD}_{\text {cit }}$ at $\lambda_{\text {ex }} 300-400 \mathrm{~nm}$, respectively.

a promising approach to synthesise CDs with good luminescence performance.

When CDs are used in cell imaging or sensing applications, it is required that the materials must be water-soluble and have a good stability in ambient environments. Thus, we tested the luminescence stability of the as-prepared CDs under different conditions, such as various ionic strengths, $\mathrm{pH}$, storage time and continuous UV irradiation (Fig. 5). It could be seen that the PL intensity of the CDs was nearly constant with the increase of ionic strength, suggesting that there was almost no ionization of the surface groups on the CDs. From the plots of PL intensity with $\mathrm{pH}(2-11)$, there was no obvious change in the PL intensity of the CDs. Furthermore, the PL intensity showed no obvious decrease even after 10 days of storage or $3 \mathrm{~h}$ of UV light irradiation, indicating the excellent storage stability and photostability of the as-prepared CDs. All these experimental data suggested that the CDs were stable even under extreme conditions.

\subsection{Construction of the chemosensor for Nim detection}

Initial experiments demonstrated that Nim could effectively quench the fluorescence of CDs. So, we can fabricate a sensitive fluorescence sensor to detect Nim based on the variation of the fluorescence intensity of CDs. To identify the selectivity of the fluorescent sensor, experiments were performed separately in the presence of a series of metal ions, amino acids and other antipyretics (including $\mathrm{Ag}^{+}, \mathrm{Ba}^{2+}, \mathrm{Fe}^{3+}, \mathrm{Fe}^{2+}, \mathrm{Ca}^{2+}, \mathrm{Cu}^{2+}, \mathrm{Cr}^{3+}$, $\mathrm{Mn}^{2+}, \mathrm{Mg}^{2+}, \mathrm{Al}^{3+}, \mathrm{Ni}^{2+}, \mathrm{Zn}^{2+}, \mathrm{Pb}^{2+}, \mathrm{Cd}^{2+}, \mathrm{Hg}^{2+}$, alanine, glycine, glutamate, ibuprofen, $p$-acetamidophenol and Nim). As shown in Fig. 6A, only Nim can lead to absolute fluorescence quenching. This result reveals that the as-prepared CDs are highly selective toward Nim over the metal ions and other antipyretics. The possible reason for this is that Nim is an electron-deficient compound due to the presence of a nitro group, and fluorescence quenching will take place when it interacts with electron-rich carbon dot fluorophores. ${ }^{37}$ More importantly, we observed the strong overlap of the fluorescence spectroscopy of the CDs with the absorption band of Nim, whereas this overlap was very weak for other substances (Fig. S3 in ESI $\dagger$ ). This verified powerfully that energy transfer happens efficiently from the CDs to Nim, and brings about fluorescence quenching of CDs.

In addition, the effect of $\mathrm{pH}$ on the sensor was also optimized, and the results revealed that the value of $F_{0} / F$ in $\mathrm{pH} 10$ $\mathrm{B}-\mathrm{R}$ buffer solution was higher than those of other $\mathrm{pH}$ values (Fig. 6B), so pH 10 was chosen for the following study. To elucidate the detailed size change of the CDs in the presence of Nim, we further measured the dynamic light scattering of CDs with and without Nim under the optimal pH condition. From
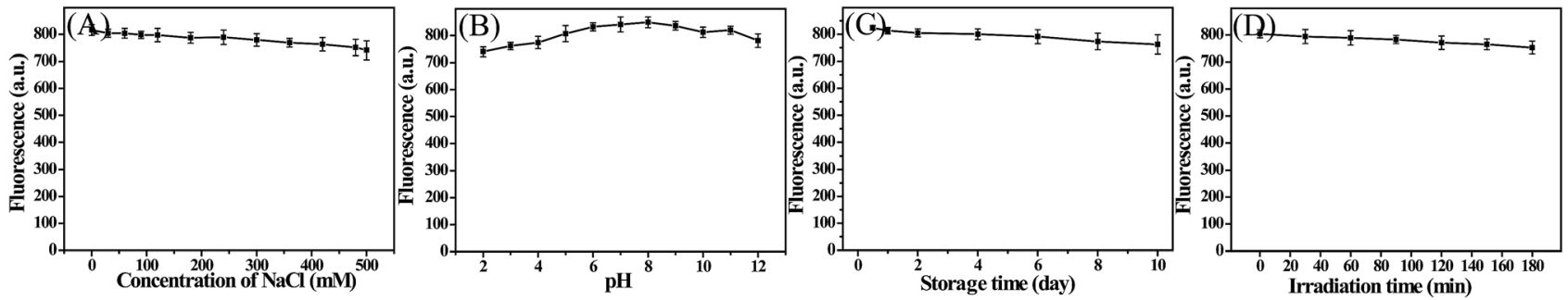

Fig. 5 Effect of ionic strength (A), pH (B), storage time (C) and UV lamp irradiation (D) on the fluorescence intensity of the CDs.
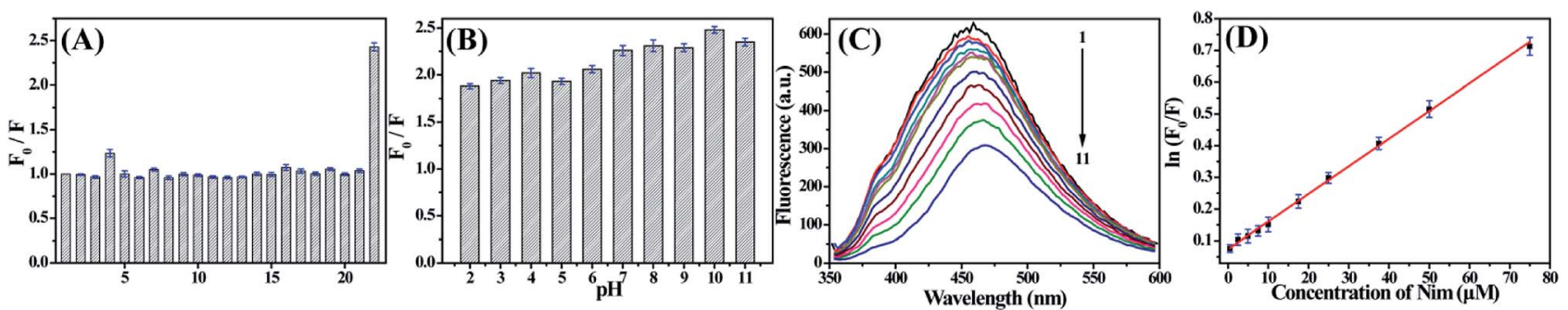

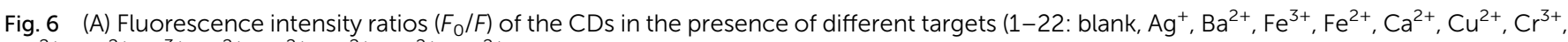
$\mathrm{Mn}^{2+}, \mathrm{Mg}^{2+}, \mathrm{Al}^{3+}, \mathrm{Ni}^{2+}, \mathrm{Zn}^{2+}, \mathrm{Pb}^{2+}, \mathrm{Cd}^{2+}, \mathrm{Hg}^{2+}$, alanine, glycine, glutamate, ibuprofen, $\mathrm{p}$-acetamidophenol and Nim). (B) The effect of $\mathrm{pH}$ on the detection of Nim based on the CDs; (C) fluorescence emission spectra of CDs in the presence of various concentrations of Nim; (D) plot of ln $F_{0}$ / $F$ of $C D$ s versus the concentration of $\mathrm{Nim}$. 
Fig. S4, $\dagger$ it can be seen that the size distributions of the CDs was $6.5 \pm 2.3 \mathrm{~nm}$, which is basically consistent with the TEM results. However, the average size dramatically varied to $204.7 \pm 2.1 \mathrm{~nm}$ while Nim was introduced, suggesting the sizes of CDs obviously increased, therefore proving that Nim combined with CDs.

Such a significant dimensional change may be ascribed to the aggregation of CDs. ${ }^{38,39}$ The surface of Nim is positively charged due to the presence of a nitro group, which is favourable for binding negatively charged CDs on the surface, thus, aggregates of CDs are formed because of the existing electrostatic attractive forces. On the other hand, hydrogen-bonding interactions may be formed between the $\mathrm{N}$ and $\mathrm{O}$ in the structure of Nim and the oxygen-containing functional groups of CDs, which would further help to form CDs aggregates. ${ }^{38,39}$

As shown in Fig. 6C and D, the fluorescence intensity of CDs decreased with the addition of CDs. A linear relationship between $\ln \left(F_{0} / F\right)$ and the concentration of Nim was obtained in the range from $0.5 \mu \mathrm{M}$ to $75 \mu \mathrm{M}$ with a detection limit of $100 \mathrm{nM}$. The linear regression equation was $\ln \left(F_{0} / F\right)=0.00872 C$ $(\mu \mathrm{M})+0.07314(R=0.9991)$.

To investigate the practicality of this developed approach, the standard recovery experiments were carried out for Nim tablets. Typically, Nim tablets were ground uniformly in a mortar, the powder $(125 \mathrm{mg})$ was dissolved into $1 \mathrm{~mL} \mathrm{NaOH}$ $\left(1 \mathrm{~mol} \mathrm{~L}^{-1}\right)$, the obtained solution was transferred to a volumetric flask (25 mL) and set the volume with pH $10 \mathrm{~B}-\mathrm{R}$ buffer solution. Various concentrations of Nim were added to CDs for further detection using the above mentioned method (Table 1). It was verified that the measured content $(3.27 \mu \mathrm{M})$ was very close to the theoretical content $(3.24 \mu \mathrm{M})$. The recovery rates of Nim are in the range 95.02-99.54\%, implying that the fluorescence method has potential applicability for the determination of Nim in pharmaceutical samples.

\subsection{Cell imaging and cytotoxicity}

An MTT assay was firstly carried out to assess the cytotoxicity of the CDs towards HeLa and ADSC cells before they were applied in optical bioimaging. The results are summarized in Fig. S5. $\dagger$ Results showed that over $90.5 \%$ of ADSC cells and over $86.8 \%$ of HeLa cells still maintained cell viability after incubation with CDs (maximum concentration: $500 \mu \mathrm{g} \mathrm{mL}{ }^{-1}$ ) for $72 \mathrm{~h}$. This sufficiently proves the extremely low cytotoxicity of the CDs. Therefore, the as-prepared CDs could be safely applied in cell imaging. Afterwards, the cellular imaging ability of CDs toward HeLa and ADSC cells were further investigated. As depicted in Fig. 7, it is clearly observed that HeLa and ADSC cells could emit strong blue fluorescence under excitation of $408 \mathrm{~nm}$, suggesting that CDs possess excellent cell membrane permeability. However, it is noticed that the fluorescence intensity in the cytoplasmic area of the cell is very strong, while it is very weak or there is even no fluorescence in the nucleus of the cell. This indicated that the CDs easily penetrate into the cell but rarely enter into the nuclei, avoiding the damage of CDs to the cell. All these results demonstrate that CDs obtained by the photoirradiation method have potential applications in cell imaging.
Table 1 Determination of Nim in pills by the proposed method $(n=3)$

\begin{tabular}{lllll}
\hline Sample & $\begin{array}{l}\text { Added Nim } \\
(\mu \mathrm{M})\end{array}$ & $\begin{array}{l}\text { Measured Nim } \\
(\mu \mathrm{M})\end{array}$ & $\begin{array}{l}\text { Recovery } \\
(\%)\end{array}$ & RSD $(\%)$ \\
\hline \multirow{2}{*}{ Pill } & 0 & 3.27 & - & 1.56 \\
& 30 & 33.50 & 99.54 & 1.25 \\
& 40 & 41.83 & 96.48 & 1.97 \\
& 50 & 50.78 & 95.02 & 2.32 \\
\hline
\end{tabular}
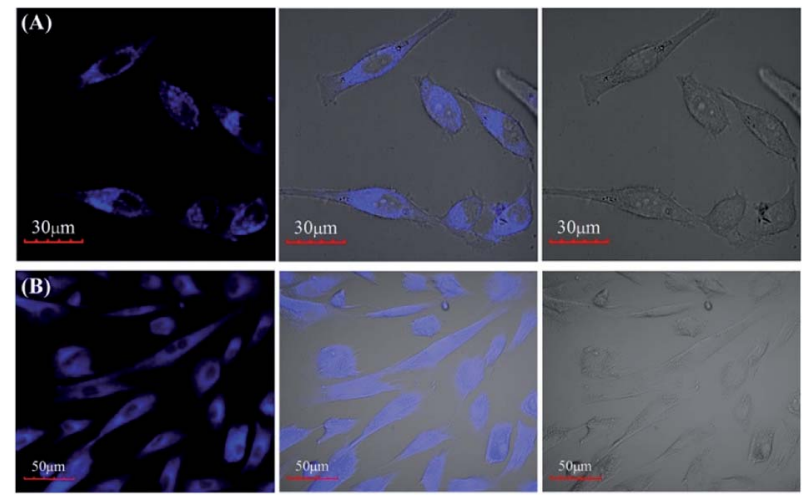

Fig. 7 Cellular imaging of HeLa cells (A) and ADSC (B) at $37^{\circ} \mathrm{C}$ for $2 \mathrm{~h}$ and $4 \mathrm{~h}$, respectively. From left to right are confocal fluorescence microphotographs, bright-field microphotographs and the corresponding overlay image, respectively. The excitation wavelength is $405 \mathrm{~nm}$.

\section{Conclusions}

In conclusion, we have successfully developed a novel strategy to synthesize fluorescent CDs for the detection of Nim firstly and for cell imaging. The as-synthesized CDs emitted bright blue fluorescence and exhibited excellent photostability and storage stability. The developed fluorescence sensor offered high selectivity for Nim over metal ions, other amino acids and antipyretics, and high sensitivity with a low detection limit (100 $\mathrm{nm}$ ). Furthermore, the as-synthesized CDs could be readily applied to the HeLa and ADSC cell imaging, exhibiting great opportunities for practical applications in biological fields.

\section{Conflicts of interest}

There are no conflicts to declare.

\section{Acknowledgements}

This work was supported by the National Natural Science Foundation of China (21301111), Research Project Supported by Shanxi Scholarship Council of China (2016-105) and the Research Foundation of Datong City (2017129).

\section{Notes and references}

1 X. Xu, R. Ray, Y. Gu, H. J. Ploehn, L. Gearheart, K. Raker and W. A. Scrivens, J. Am. Chem. Soc., 2004, 126, 12736-12737. 
2 P. Pierrat, R. Wang, D. Kereselidze, M. Lux, P. Didier, A. Kichler, F. Pons and L. Lebeau, Biomaterials, 2015, 51, 290-302.

3 H. Ding, S. B. Yu, J. S. Wei and H. M. Xiong, ACS Nano, 2016, 10, 484-491.

4 L. Yang, Z. Wang, J. Wang, W. Jiang, X. Jiang, Z. Bai, Y. He, J. Jiang, D. Wang and L. Yang, Nanoscale, 2016, 8, 6801-6809.

5 W. Gao, Y. Ma, Y. Zhou, H. Song, L. Li, S. Liu, X. Liu, B. Gao, C. Liu and K. Zhang, Mater. Lett., 2018, 216, 84.

6 X. Y. Liu, H. Chen, R. Wang, Y. Shang, Q. Zhang, W. Li, G. Zhang, J. Su, C. T. Dinh and F. de Arquer, Adv. Mater., 2017, 29, 1605646.

7 Y. Sun, B. Zhou, Y. Lin, W. Wang, K. A. S. Fernando, P. Pathak, M. J. Meziani, B. A. Harruff, X. Wang, H. Wang, P. Luo, H. Yang, M. E. Kose, B. Chen, L. M. Veca and S. Xie, J. Am. Chem. Soc., 2006, 128, 7756-7757.

8 S. Hu, K. Niu, J. Sun, J. Yang, N. Zhao and X. Du, J. Mater. Chem., 2009, 19, 484-488.

9 J. Lu, J. Yang, J. Wang, A. Lim, S. Wang and K. P. Loh, ACS Nano, 2009, 3, 2367-2375.

10 J. Zhou, C. Booker, R. Li, X. Zhou, T. K. Sham, X. Sun and Z. Ding, J. Am. Chem. Soc., 2007, 129, 744-745.

11 Y. Yang, J. Cui, M. Zheng, C. Hu, S. Tan, Y. Xiao, Q. Yang and Y. Liu, Chem. Commun., 2012, 48, 380-382.

12 R. Liu, D. Wu, S. Liu, K. Koynov, W. Knoll and Q. Li, Angew. Chem., Int. Ed., 2009, 48, 4598-4601.

13 H. Li, X. He, Y. Liu, H. Huang, S. Lian, S. T. Lee and Z. Kang, Carbon, 2011, 49, 605-609.

14 J. Zhang, W. Shen, D. Pan, Z. Zhang, Y. Fang and M. Wu, New J. Chem., 2010, 34, 591-593.

15 S. Chandra, P. Das, S. Bag, D. Laha and P. Pramanik, Nanoscale, 2011, 3, 1533-1540.

16 K. V. Anikin, N. N. Melnik, A. V. Simakin, G. A. Shafeev, V. V. Voronov and A. G. Vitukhnovsky, Chem. Phys. Lett., 2002, 366(3-4), 357-360.

17 R. Zhang and W. Chen, Biosens. Bioelectron., 2014, 55, 83-90.

18 M. Carini, G. Aldini, R. Stefani, C. Marinello and R. M. Facino, J. Pharm. Biomed. Anal., 1998, 18, 201-211.

19 G. Khaksa and N. Udupa, J. Chromatogr. B: Biomed. Sci. Appl., 1999, 727, 241-244.

20 V. D. Mody, K. K. Pandya, M. C. Satia, I. A. Modi, R. I. Modi and T. P. Gandhi, J. Pharm. Biomed. Anal., 1998, 16, 12891294.
21 B. S. Nagaralli, J. Seetharamappa, B. G. Gowda and M. B. Melwanki, J. Anal. Chem., 2003, 58, 778-780.

22 M. Florea, C. M. Monciu and M. Ilie, Anal. Lett., 2015, 48, 328-339.

23 D. Thomas, L. Lonappan, L. Rajith, S. T. Cyriac and K. G. Kumar, J. Fluoresc., 2013, 23, 473-478.

24 P. F. Pereira, M. C. Marra, A. B. Lima, W. T. Pio dos Santos, R. A. A. Munoz and E. M. Richter, Diamond Relat. Mater., 2013, 39, 41-46.

25 J. L. Zhang, X. C. Tan, D. D. Zhao, S. W. Tan, Z. W. Huang, Y. Mi and Z. Y. Huang, Electrochim. Acta, 2010, 55, 25222526.

26 M. Govindasamy, V. Mani, S. M. Chen, T. Maiyalagan, S. Selvaraj, T. W. Chen, S. Y. Leee and W. H. Changfgh, RSC Adv., 2017, 7, 33043-33051.

27 P. B. Deroco, R. C. Rocha-Filho and O. Fatibello-Filho, Talanta, 2018, 179, 115-123.

28 C. Y. Wang, X. Q. Shao, Q. X. Liu, Q. S. Qu, G. J. Yang and X. Y. Hu, J. Pharm. Biomed. Anal., 2006, 42, 237-244.

29 L. Miranda, V. C. Pereira, C. S. Machado, Y. R. Torres, V. E. dos Anjos and S. P. QuináI, Arch. Environ. Contam. Toxicol., 2017, 73, 631-640.

30 S. Furlanetto, S. Orlandini, G. Aldini, R. Gotti, E. Dreassi and S. Pinzauti, Anal. Chim. Acta, 2000, 413, 229-239.

31 S. Menon and K. G. Kumar, J. Electrochem. Soc., 2017, 164, B482-B487.

32 F. W. P. Ribeiroa, T. R. V. Soaresa, S. D. N. Oliveiraa, L. C. Melo, J. E. Soares, H. Becker, D. D. Souza, P. D. LimaNeto and A. N. Correiaa, J. Anal. Chem., 2014, 69, 62-71.

33 S. D. Bukkitgar, N. P. Shetti, R. M. Kulkarni and M. R. Doddamani, J. Electroanal. Chem., 2016, 762, 37-42.

34 Y. Zhang, T. Qu, K. Xiang, Y. Shen, S. Chen, M. Xie and X. Guo, J. Mater. Chem. A, 2018, 6, 2353-2359.

35 J. Liang, T. Qu, K. Xiang, Y. Zhang, S. Chen, Y. C. Cao, M. Xie and X. Guo, Appl. Surf. Sci., 2018, 436, 934-940.

36 Y. He, J. He, Z. Yu, H. Zhang, Y. Liu, G. Hu, M. Zheng, H. Dong, J. Zhuang and B. Lei, J. Mater. Chem. C, 2018, 6, 2495-2501.

37 H. K. Sadhanala and K. K. Nanda, J. Phys. Chem. C, 2015, 119, 13138-13143.

38 X. Liu, J. Li, Y. Huang, X. Wang, X. Zhang and X. Wang, Environ. Sci. Technol., 2017, 51, 6156-6164.

39 W. Yang, J. Ni, F. Luo, W. Eeng, Q. H. Wei, Z. Lin and G. Chen, Anal. Chem., 2017, 89, 8384-8390. 